\title{
Improving the Restructuring of Distressed Assets Through Securitization on Emerging Markets
}

\author{
Olga Em
}

\begin{abstract}
This article reveals the concept of asset securitization as one of the mechanisms for improving the business through the transfer of selected, homogeneous assets to a special financial purpose vehicle. The definitions of the types of mechanisms for restructuring and improving enterprises in Kazakhstan are given. It is concluded that the asset securitization mechanism can be successfully applied in a rapidly changing business environment, and can also be used widely enough for companies to attract an additional long-term funding source.

Index Terms - securitization, risk management, capital markets, stock market, bond issue, restructuring, credit risk, special purpose vehicle
\end{abstract}

\section{INTRODUCTION}

Nowadays Kazakhstani stock market may prove to be a worthy alternative financial sector, which diversifies the base for attracting long-term financing, both for speculators and for strategic investors.

The international rating agency S\&P Global Ratings recently confirmed the long-term and short-term sovereign credit ratings in foreign and national currency of Kazakhstan at the level of BBB-/A-3. The agency expects that the country's sovereign and external balance to remain viable.

However, after a series of high-profile defaults and a wave of subsequent restructurings that took place in 2008 2009 , it has a narrow limited toolkit and still provides access only to a certain variety of poorly illiquid quasi-state institutional players.

The current state of the economy of Kazakhstan allows, on the one hand, to improve risk management mechanisms, and on the other hand, to introduce alternative investment tools that have already proved themselves from the best abroad, which allow to find alternative sources of financing for business.

In the period from 2000 to 2007, second-tier banking system of the Republic of Kazakhstan acted as the most active and innovative part in terms of attracting liquidity in the stock market. Commercial banking put together and transferred bad assets to the balance of a new created special financial institution through the securitization mechanism. These assets were formed into a homogeneous pool and had the same properties in terms of credit risk exposure. For example, such an asset could be mortgage loan with the same maturity, interest rate. Further, a special financial company (the abbreviation from SPV stands for special purpose vehicle), under the provision of these assets, issued

Revised Manuscript Received on July 18, 2019.

Olga Em, 3rd year PhD Student, Department: Business administration, Almaty Management University, Almaty, Kazakhstan. (e-mail: olgaem@vitisadvisor.com) bonds and, through their placement, attracted liquidity, which transferred to a commercial bank. Various bond credit ratings could be assigned to different bond issues, reflecting the risk of default and the likelihood of full redemption of these debt securities.

\section{THEORETICAL ISSUES}

The term "securitization" is formed from the word "securities": it is a type of financial instrument. Securitization is the process of financing an enterprise for the assignment of a monetary claim by issuing bonds secured by dedicated assets [4].

Bond (Latin obligatio - obligation; English bond - longterm, note - receipt) - by issuing debt security, the owner of which has the right to receive from the person who issued it (the issuer of the bond), in the stipulated time frame, its nominal value in cash or otherwise property equivalent. Also, a bond may provide for the right of the owner (holder) to receive a percentage (coupon) of its nominal value or other property rights. The investor's income can consist of two components: periodic payments in the agreed amount (coupon yield) and the difference between the purchase price of the bond and the repayment price (discount income). Often there are bonds with a floating interest rate, which is tied to the rates of the interbank market, refinancing or other financial indicators.

One of the most vivid, real-life examples is the Kazakhstan Mortgage Company JSC (currently, the main shareholder is Baiterek JSC), which from the very beginning of its foundation acted as a mortgage agent and issued mortgage bonds (mortgage backed securities), which were secured the rights of claims on long-term mortgage loans. In 2002, the first mortgage bonds were issued, which allowed the company to attract new liquidity and provide it to second-tier banks through the subsequent redemption of rights of claim.

In the period 2008-2009, large commercial Kazakhstani banks faced a default on their debt obligations, a subsequent decrease in credit ratings and could not completely reduce their debt burden in time and improve their own balance. Some of the assets on mortgage loans were restructured, some of the debts were written off, but the situation has not changed in a positive direction over the past five years. The requirement of the local financial regulator in the person of National bank of Kazakhstan to increase the capitalization 


\section{IMPROVING THE RESTRUCTURING OF DISTRESSED ASSETS THROUGH SECURITIZATION ON EMERGING MARKETS}

of the banking sector has noticeably tightened the limits, and now it is FPK JSC (troubled loan fund) that bears the main burden on releasing distressed long-term assets and their subsequent restructuring of stressful assets.

At the same time, lending to the economy in the real sector has noticeably slowed down, and the corporate segment of medium-sized and large-cap companies every year suffers from a deficit of long-term funding to ensure further business growth.

However, country credit ratings have recovered, and in the Kazakhstan banking sector over the period 2016-2018, long-term investor confidence is still at the minimum critical levels. This is due to unresolved issues related to the minimization of credit risks and the recovery of debt obligations of the second-tier banks themselves.

The tremendous liquidity of cash placed on deposits in second-tier banks is accumulated in correspondent accounts with the National Bank of the Republic of Kazakhstan starting in 2015 and is not redistributed for lending to Kazakhstan business. The problem lies precisely in the reluctance of banks to bear the increased credit risks associated with the ability to service the debt and are quite comparable with the current state of the economy. The rate of return on the notes of National Bank of Kazakhstan covers inflationary expectations and makes it impossible to bear the increased credit risks of already problematic enterprises that did not solve the problems of a decade ago and stagnate due to the lack of opportunity to refinance default loans.

As a result of stagnant intra-economic processes, some Kazakhstani enterprises are beginning to independently develop and find alternative sources for the search for medium-term funding. Thus, through the allocation, transfer and subsequent sale of less-liquid assets, it is possible to attract medium-term liquidity through new long-term financial instruments.

Below is the classic scheme of the asset securitization transaction:

Figure 1. Classic asset securitization mechanism
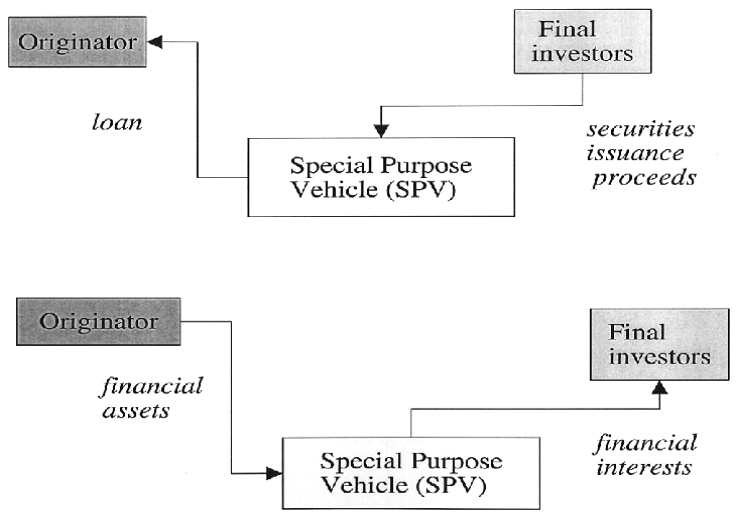

On the practical side of this issue, there are no restrictions on the use of this asset securitization scheme. As assets can be any property rights, whether it be car loans, leasing payments, intellectual property rights.

In turn, assets must meet certain credit risk properties: to be homogeneous, to generate stable calculated and projected cash flows, and also have the ability to be legally separated from the originator. Originator is a legal entity performing the assignment of rights of claim when concluding a securitization transaction [4].

Currently, Kazakhstani legislation allows local securitization transactions with various types of assets on the balance sheet of an enterprise. This gives additional impetus to the development of more advanced exotic financial instruments.

\section{DISCUSSION \& RESULTS}

All the advantages and benefits for the potential investorbondholder consider further. First of all, the investor manages operational risk through a transparently regulated infrastructure. The protection of the regulator is formalized through several Kazakhstani laws: "On joint-stock companies", "On the securities market", "On securitization and project financing". The custodian bank is the custodian that maintains records of the assets allocated, and a coupon payment is paid from the custodial account to the bondholders and the principal amount is repaid. Asset audits are conducted on an annual basis by both the originator and the special purpose company. The law provides for the function of a representative of bondholders: it can be performed by a licensee-broker-dealer. It is this financial institution that provides the quarterly report to the regulator on solvency and prevents the risk of default by the issuing company.

Secondly, collateral (rights of claim) on debt securities provides an opportunity to minimize the credit risks on the part of the issuer.

Thirdly, the investor has the full right to implement this instrument in the secondary stock market. Thus, the potential investment attractiveness of bonds of a special financial company provides additional liquidity to current investors-lenders.

Fourth, for individual investors, exemption from individual income tax is still provided. Remuneration on coupon bonds in Kazakhstan is taxed-exempt and taken into account at a zero rate. Tax optimization in accordance with the Kazakhstan legal field has a positive effect on the issue and placement of these securities for the development of a number of securitization of assets of new issuers.

It is impossible not to note the possible disadvantages in the implementation of this alternative financing for the banking sector of Kazakhstan. On closer examination, the scheme no longer looks so unambiguous due to several factors. When conducting securitization, the procedures related to the quality assessment and the fair value of securitized loans are quite important. Doubts about the official estimates of the quality of bank assets are weighty today. On the underestimated level of problem loans (NPL non performing loans) of Kazakhstan banks with enviable consistency, all rating agencies say. The reserves and provisions accrued and reflected in the equity capital of the bank are one of the indicative indicators of the real financial position of the balance. Under these conditions, there are concerns that banks have the ability to deliberately

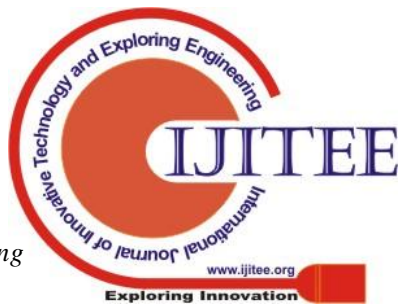


overestimate the quality of assets included in pools of securitized loans, which will allow them to some extent manipulate regulatory financial reporting. This factor should be taken into account when assigning a rating in assessing the quality of securitized assets.

It should be noted that the above-described asset securitization mechanism is of particular value today, as it allows not only to attract additional funding, but also to heal stressful assets on the balance sheet of the company, which reduce the investment attractiveness of the business itself.

The development of the local asset securitization market will allow attracting international investments.

\section{CONCLUSION}

It is obvious to set up that for the successful development of the local asset securitization market in Kazakhstan, it is necessary to eliminate the imperfections of Kazakhstani legislation and develop new legislation in the field of asset securitization. In the short term, local asset securitization has the potential to be used as an effective tool for implementing anti-crisis measures in the Kazakhstani economy. Right now, the urgent need of both one hundred investors and companies from the real sector, the diversification in the provision of new investment instruments will improve liquidity and give a new impulse for the development of the Kazakh economy and GDP growth in the country in the nearest future.

\section{REFERENCES}

1. Law of the Republic of Kazakhstan dated July 02, 2003 No. 461-II (With amendments and additions as of February 27, 2017), Almaty 2003 "On the Securities Market"

2. Law of the Republic of Kazakhstan dated May 13, 2003 No. 415-II (With amendments and additions as of February 27, 2017). Almaty 2003 "On Joint-Stock Companies"

3. Law of the Republic of Kazakhstan "On Rehabilitation and Bankruptcy" (with amendments and additions as of 07/02/2018)

4. Law of the Republic of Kazakhstan dated February 20, 2006 No. 126. (with amendments and additions as of February 27, 2017) "On project financing and securitization"

5. Kase.kz

6. Nationalbank.kz 